\title{
José Bezerra Gomes: o romance quer ser poema
}

José Américo Miranda Universidade Federal de Minas Gerais

\begin{abstract}
Resumo: Este artigo passa em revista a obra do poeta e romancista José Bezerra Gomes, assinalando a vocação poética do escritor, que, mesmo em seus romances, tendia para a densidade própria dos textos poéticos. Palavras-chave: Romance brasileiro de 30, Ficção regionalista, José Bezerra Gomes.
\end{abstract}

No ciclo do romance nordestino, que assinalou a década de 1930 na literatura brasileira, o Rio Grande de Norte teve uma parte pequena, mas não desinteressante nem indigna da grande ficção daquele tempo. O escritor norte-rio-grandense que apresentou a região produtora de algodão, a região do Seridó, no quadro da ficção brasileira, foi José Bezerra Gomes.

As notícias disponíveis sobre o romancista e poeta (ele também escreveu poesia), apesar das facilidades de que dispomos hoje para obter informações, e apesar das reedições relativamente recentes de sua obra, são poucas e de difícil acesso. Eis os dados que se podem reunir com certa facilidade. Não há verbete dedicado a ele no importante Dicionário literário brasileiro, de Raimundo de Meneses, como nada há sobre ele no também importante Pequeno dicionário de Literatura Brasileira, organizado por José Paulo Paes e Massaud Moisés. Tampouco o mencionam a volumosa História crítica do romance 
brasileiro, em três alentados volumes, de Temístocles Linhares, e a História da inteligência brasileira, em sete volumes, de Wilson Martins - obra esta de vocação enciclopédica. Seu nome não aparece em A literatura no Brasil, obra em seis volumes, idealizada e organizada por Afrânio Coutinho.

Onde ele aparece, então? - é de se perguntar. Em primeiro lugar, honrosamente para a obra, na Enciclopédia de Literatura Brasileira, em dois volumes, dirigida por Afrânio Coutinho e J. Galante de Sousa. Em segundo, em obras dedicadas à literatura do Rio Grande do Norte, como, por exemplo, a antologia Literatura do Rio Grande do Norte, organizada pelas professoras Constância Lima Duarte e Diva Maria Cunha Pereira de Macedo, e A poesia e o poema do Rio Grande do Norte, de Moacy Cirne. Em terceiro, no trabalho monográfico, único no gênero sobre o tema, Uma história do romance de 30, em que Luís Bueno aborda o romance Os brutos no quadro de seu tempo.

O verbete da Enciclopédia de Literatura Brasileira é minúsculo, e traz poucas informações (v. I, p. 672):

GOMES, José Bezerra (Currais Novos, RN, ? - ), poeta, romancista, ensaísta, dipl. Direito, advogado. BIBL.: Os brutos. 1935 (rom.); Por que não se casa, doutor (rom.); Retrato de Ferreira Itajubá. 1944. (biogr. crít.); A porta e o vento. 1974 (rom.); Antologia poética. 1974 (poes.). REF.: Cirne. Poes. RN, 16, 29; Onofre Júnior Est. RN, 109, 126; Vanderlei Panorama, 76; Fusco, Rosário. Vida literária. 1940. p. 146; Jurema, Aderbal. Provincianas. 1a. Série. 1949. p. 128-131.

As informações são escassas, lacunares, e às vezes erradas. O verbete não traz a data de nascimento: segundo outras fontes, o romancista nasceu em Currais Novos, RN, em 9 de março de 1911. O livro Centenário de José Bezerra Gomes traz fac-símile do registro civil comprobatório da informação. ${ }^{1} \mathrm{O}$ verbete não traz local nem data da morte: o romancista morreu em Natal, RN, no dia 26 de maio de $1982{ }^{2}$ O verbete dá o romance Os brutos, justamente aquele que pertence ao ciclo nordestino dos anos 30, como tendo sido publicado em 1935: o romance é de 1938. O verbete menciona o romance Por que não se casa, Doutor?, e não dá mais informações. O romance foi publicado em 1944,

1. Cf. SouzA. Centenário de José Bezerra Gomes, p. 41.

2. Cf. SouZA. Centenário de José Bezerra Gomes, p. 125. 
pelas edições Surto, Natal, ${ }^{3}$ e Joabel R. de Souza dá notícia de uma segunda edição em $1945{ }^{4}$

As demais informações do verbete estão corretas, sendo as fontes pouco numerosas. O que mais se sabe, além do fato de haver ele concorrido com Guimarães Rosa a uma cadeira na Academia Brasileira de Letras? Sabe-se que José Bezerra Gomes estudou Direito e formou-se em Belo Horizonte, na antiga Universidade de Minas Gerais, atual UFMG. O documento que comprova sua matrícula em 1932 e a lista dos bacharelandos de 1936 da Faculdade de Direito de Minas Gerais encontram-se reproduzidos em O centenário de José Bezerra Gomes. ${ }^{5}$ Outros trabalhos seus são: Retrato de Ferreira Itajubá, ensaio publicado pelas edições Surto, em Natal, em 1944; Teatro de João Redondo, sobre o teatro de bonecos do "João Redondo", o mamulengo do Rio Grande do Norte, publicado em Natal, 1975, pela Fundação José Augusto. ${ }^{6}$ O romance $A$ porta e o vento e a Antologia poética apareceram em 1974, ambos pela mesma Fundação José Augusto. Em 1975, impresso na Manimbu, em Natal, saiu a Sinopse do município de Currais Novos (Monografia ilustrada). O estudo Retrospecção da vida do presidente Tomás de Araújo Pereira apareceu em Natal, em 1981, em separata do I. H. G. R. N. Mais recentemente, a Editora da Universidade Federal do Rio Grande do Norte publicou num só volume - Ensaios reunidos (2004) - o "Retrato de Ferreira Itajubá" e o "Teatro de João Redondo" - com as notas, que nas primeiras edições vinham ao final de cada capítulo ou parte dos ensaios, reunidas no fim de cada ensaio.

Segundo Luís Carlos Guimarães, no "Prefácio" às Obras reunidas: Romances (1998), as narrativas de Os brutos (1938) e A porta e o vento (1974), juntamente com o ainda inédito Ouro branco, comporiam um ciclo do algodão - o que daria ao Rio Grande do Norte, no plano da ficção, um ciclo semelhante ao da cana-de-açúcar, que José Lins do Rego deu à Paraíba, e ao do cacau, que Jorge Amado e outros deram à Bahia.

3. Cf. GOMES. Obras reunidas: Romances, última capa.

4. Cf. SouZA. Centenário de José Bezerra Gomes, p. 24.

5. Cf. SOUZA. Centenário de José Bezerra Gomes, p. 67 e p. 69.

6. Cf. GOMES. Obras reunidas: Romances, última capa.

7. Cf. GOMES. Obras reunidas: Ensaios, 2004.

8. A existência do manuscrito foi confirmada, pela seguinte mensagem eletrônica enviada em 16 de agosto de 2012 ao autor deste artigo pela Direção da Fundação José Bezerra Gomes, de Currais Novos: "O romance inacabado intitulado Ouro Branco existe sim como acervo em nosso museu." 
Dessas obras há as seguintes reedições: o romance Os brutos foi reeditado em 1981, pela Universidade Federal do Rio Grande do Norte, e, em 2007, pelas edições Sebo Vermelho, de Natal; os romances todos foram reunidos no volume Obras reunidas: Romances (Natal: EDUFRN, 1998).

Sobre o autor, há a plaquete José Bezerra Gomes - sua vida e sua obra (Fundação Cultural José Bezerra Gomes, Currais Novos; Cortez Editora, São Paulo, 1994), obra de difícil acesso. Em 2011, a mesma Fundação José Bezerra Gomes, associada à Prefeitura Municipal de Currais Novos, publicou, para celebração da data, o livro Centenário de José Bezerra Gomes, obra de Joabel R. de Souza - que acrescenta inúmeras informações aos tão poucos dados disponíveis sobre o escritor.

O romance Os brutos, que se pode dividir em duas partes (embora o texto não apresente essa divisão), tem 25 capítulos e é narrado por um menino. $\mathrm{Na}$ primeira parte, que vai do primeiro ao décimo quarto capítulo, o menino está em Currais Novos, às margens do rio Seridó, em época de cheia (inverno) e prosperidade. Ele tinha ido para a cidade estudar, morava com um casal de tios. Diversos tipos da cidade aparecem no romance: o usurário Seu Tota Alves, riquíssimo, com seu motorista Jesus - que fazia sucesso na cidade, "tinha uma namorada em cada ponta de rua"; Seu Barão e sua mulher, que "namorava os homens na vista do marido"; tio Lívio, que mata sua amante prostituta, a Rica, e vai para a cadeia, onde enlouquece; os presos da cadeia; os tios com quem morava o menino que narra, tia Maria e tio Abdias, farmacêutico; o filho do casal, Aldair, "um menino louro de tranças de boneca", que era criado junto à saia da mãe; o sacristão, que tinha fama de virgem e, para desforrar-se, tem sua primeira experiência sexual com as prostitutas do Aterro; os meninos que estudavam fora (em Natal, no Recife ou na Bahia) e voltavam no final do ano; e os moleques de rua, companheiros do narrador, dos quais ele se despede no capítulo décimo quinto - em que começa a segunda parte do romance.

"Uma tarde, no entanto, sem tia Maria esperar, chegou um portador a cavalo do Alívio, para me levar." - diz o narrador, anunciando sua ida para o sítio dos pais, o Alívio. Ali ele reencontra a família, num sítio em construção, que o pai herdara pela morte do avô. Faziam um açude, tinham algodão

9. SOUZA. Centenário de José Bezerra Gomes, 2011.

10.GOMES. Obras reunidas: Romances, 1998, p. 41. 
plantado. O menino tenta abordar sexualmente as filhas de um agregado. Um dos trabalhadores do açude o instrui sobre isso e o incentiva. Os destinos de seus diversos tios são mencionados. Entretanto, vem a seca e o sítio está hipotecado ao seu Tota:

Os roçados botados de novo, as cercas em pé, o açude acabado e nada de chover. Mal neblinou, a terra não molhou e o açude sem um pingo d'água. As aves deixaram de cantar e os matos secaram. Quando mais o Alívio precisou de chuva para as suas terras, o inverno faltou.

Só para seu Tota foi bom. Um ano de seca lhe rendia mais do que um ano de safra, de fartura. Fazia os melhores negócios pela hora da morte, tomando as terras dos seus devedores atrasados pelos preços que queria. Papai, a conselho de mamãe, botou a sela num cavalo e ainda foi conversar com seu Tota, em Currais Novos, e seu Tota o recebeu de braços abertos. Não queria o sítio. Não lhe interessava. Precisava sim do seu dinheiro, dos trinta contos que tinha emprestado, pois estava em aperto para fazer uns pagamentos nos bancos em Natal e necessitava receber o que lhe deviam. E deu mais um mês a papai que podia procurar um comprador para o Alívio, que era um sítio bom e com a venda lhe pagasse.

Papai voltou desanimado para casa. ${ }^{1}$

Passagens como essa, em que o narrador relata o que sucedeu em sua ausência, como se fosse um narrador onipresente - justamente o aspecto abordado por Luís Bueno nas páginas que dedica a S brutos $^{12}-$, não causam estranheza ao leitor. A razão disso? É que a individualidade do menino tem um quê de tosca, de modo que ele partilha com todos o interesse de todos. Ele é fortemente vinculado ao grupo familiar, à gente da cidade, a todas as pessoas que conhece e com quem convive. Reside nisso uma interessante questão: teria o romancista em si o "sentimento do mundo"? Em romancistas fortemente individualistas, como Lúcio Cardoso, por exemplo, o mesmo "desvio" da perspectiva narrativa causa enorme incômodo, tornando o romance (Maleita, no caso), aos olhos do leitor, uma obra problemática, defeituosa em sua estrutura.

O sítio acaba sendo entregue a seu Tota - não sem antes o pai do menino (seu Cipriano) tentar conservar a propriedade nas mãos da família,

11. GOMES. Obras reunidas: Romances, 1998, p. 53.

12. Cf. BUENO. Uma história do romance de 30, p. 444-447. 
oferecendo-a ao sogro pelo valor da hipoteca. Da condição senhorial a família passa à condição de agregada; o capataz de seu Cipriano passa a capataz de seu Tota. Seu Cipriano, no entanto, consegue passagens de navio para o sul. O romance termina com a família já dentro do navio, no porão:

O dia tinha amanhecido e Natal ia ressurgindo dentro da manhã de sol, clareando nos morros, nas Docas, na Praia da Limpa, e o Forte dos Reis Magos e o Farol da Boca da Barra foram ficando para trás. Agora era só mar, mar e céu, céu e mar. ${ }^{13}$

Rosário Fusco, que avaliou o romance em 1938, não gostou, e escreveu o seguinte:

Não há sequência nas páginas de "Os brutos", não há precisão nos seus capítulos, não há, enfim, interesse na sua leitura. Fechado o livro, não nos fica nada, a não ser o desgosto do tempo perdido inutilmente com um volume que nem como exercício literário mereceria classificação. ${ }^{14}$

Quando da reedição do romance, em 1981, escreveu Paulo Dantas, no Suplemento Literário do Minas Gerais - já mais distanciado no tempo:

Os brutos é novela que não deve favor a ninguém, podendo, como bem escreve o comunicador universitário, Ney Leandro de Castro, figurar ao lado da trilogia nordestina: Menino de Engenho, 1932, Cacau, 1933 e São Bernardo, 1934, seu parente mais próximo ou, espiritual e estilisticamente, mais chegado.

$[\ldots]$

Escreve como um grande desgraçado, escreve bem e certo, direto e nada apavonado. Suas penas são outras, suas buscas foram outras. ${ }^{15}$

Apesar da opinião desfavorável de Rosário Fusco, uma qualidade é reconhecível na ficção de José Bezerra Gomes - qualidade que a aproxima da poesia: é o notável poder de síntese com que o escritor a compõe. Esse poder

13. GOMES. Obras reunidas: Romances, 1998, p. 61.

14. FUSCO. Vida literária, 1938, p. 146.

15. DANTAS. Romancista nordestino do ciclo do algodão, 1982, p. 8. 
manifestou-se especialmente na poesia, em que compôs excelentes poemasminuto, à maneira de Oswald de Andrade. Veja-se este poema:

\title{
SEMPRE SÁBADO
}

\author{
Naquele \\ sábado \\ a música \\ daquele \\ sábado $^{16}$
}

Ou este:

PARIS

Uma

maçã

no caminho ${ }^{17}$

Essa poesia esteve no foco da atenção dos vanguardistas das décadas de 1960 e 1970, tendo sido publicada nas páginas do Suplemento Literário do Minas Gerais, periódico sempre simpático à experimentação no campo da poesia e da literatura. Nas páginas desse jornal, em maio de 1973, Moacy Cirne apresentou uma antologia da poesia do autor, e, em março de 1974, escreveu, de acordo com o espírito daquela época:

[...] a obra de José Bezerra Gomes resume-se criativamente em 8 ou 9 poemas, e que - como qualquer outra obra fundamentada no verso - apresenta um interesse puramente arqueológico para a crítica e a vanguarda literária conscientes.

Contudo, estes 8 ou 9 poemas valem por quase toda a literatura norterio-grandense anterior a $1960 .^{18}$

16. GOMES. Antologia poética, 1974, p. 52.

17. GOMES. Antologia poética, 1974, p. 51.

18. CIRNE. José Bezerra Gomes e a vanguarda, 1974, p. 11. 
Encontra-se, entre os "8 ou 9" textos citados pelo crítico, um poema sobre a cidade de Belo Horizonte, que, por essa razão, aponta para o segundo romance do autor:

\author{
BELO HORIZONTE \\ Pardais \\ cantam \\ dentro da madrugada \\ Amanhecendo \\ todos \\ vão de encontro à vida ${ }^{19}$
}

Além de realizar o nexo entre a poesia e o segundo romance do autor, esse poema sobre Belo Horizonte faz lembrar outro poeta, mineiro, oswaldiano como José Bezerra Gomes, contemporâneo dele, cujo destino na memória literária tem sido semelhante ao do escritor do Rio Grande do Norte. Trata-se de Otávio Dias Leite, que, em seu livro Baganas, de 1934, deixou este poema (entre muitos outros), em tudo semelhante aos de José Bezerra Gomes:

SESTA

O gato dormia no

Jardim. A moça na janela

Olhava a paisagem. ${ }^{20}$

A ação do romance Por que não se casa, Doutor?, publicado em 1944, passa-se em Belo Horizonte, onde o autor havia estudado Direito. O narrador é um funcionário público, um amanuense, chamado Flávio, que se forma em Direito e reside numa pensão. Ele passa as noites em bares e bordéis; não segue a profissão depois de formado, por incapacidade para tomar decisões e de dar um rumo definido a sua própria vida. Na descrição da cidade de Belo Horizonte, reaparecem elementos do poema, como os pardais e as pessoas, pela manhã, indo ao encontro da vida e suas lutas:

19. GOMES. Antologia poética, 1974, p. 48.

20. LEITE. Poesia, 1967, p. 18. 
Estou sem sono e erro dentro da madrugada fria. Sinto fome e tenho os bolsos vazios. Os últimos níqueis se foram com os cigarros. Caminho como uma pessoa ferida.

Diminuo o passo. Encontro varredores de rua. As vassouras chiam no calçamento. Os pés me doem nos sapatos. As pernas afrouxaram e ando morosamente. Chego à Praça Sete. Ainda faltam inúmeros quarteirões para a pensão. Sento-me num banco. Tiro os sapatos e acaricio os dedos dos pés. A cidade, toda iluminada, dava a impressão de uma nuvem de pássaros de fogo, pousados dentro da noite.

Um vulto passa distante. Os primeiros bondes voltam a correr. Devotas, contritas, caminham para a missa das cinco horas da Matriz de S. José. Apitos de locomotivas na Estação Central do Brasil. No asfalto ferraduras sincronizam um galope de animal misturado com rodas. Uma carrocinha de pão se aproxima trepidante. Lembro-me de que ainda tenho um tostão num dos bolsos. Aperto a moeda e faço um sinal. O padeiro para a carrocinha. Compro um pão e saio mastigando.

Os pardais cantam festivos na avenida arborizada. O clarão solar desponta sanguíneo. A cidade ressurge dentro dele. Os pardais redobram o seu canto matinal. Os meus colegas dormiram a noite toda e virão ao encontro do dia. ${ }^{21}$

Esse personagem boêmio refere-se a si próprio nos seguintes termos: "Penso no aumento de vencimentos, penso na minha vida, penso em fazer alguma coisa e abaixo a cabeça vencido.” ${ }^{22}$ Ou assim:

"Sou um bacharel fracassado, vivendo da burocracia."

"Vergo-me sob o volume do meu fracasso."

"Não tenho ânimo para nada e temo a vida."

"Sinto a necessidade de me acomodar na vida. Por que não desposei Angélica? Por que não desfrutei Magda? Por que não tomava a carioca do tísico? Sou um homem sem mulher e quando aparece uma na minha existência, encolho-me como um caracol, cheio de pânico, incapaz de uma atitude., ${ }^{23}$

21. GOMES. Obras reunidas: Romances, 1998, p. 83-84.

22. GOMES. Obras reunidas: Romances, 1998, p. 105.

23. GOMES. Obras reunidas: Romances, 1998, p. 121, p. 144, p. 146, p. 174. 
É assim a história desse bacharel, que só encontra alívio na bebida. Mas nas páginas do livro, apesar do recurso musical das repetições (o personagem é um obsessivo), há passagens verdadeiramente poéticas - à maneira do poeta José Bezerra Gomes, um poeta oswaldiano, mas que não fazia alarde disso (ser oswaldiano foi motivo de ostentação, de presunção e de vanglória para diversas gerações de poetas ao longo do século XX). Veja-se este parágrafo do oitavo capítulo, desmembrado aqui em versos:

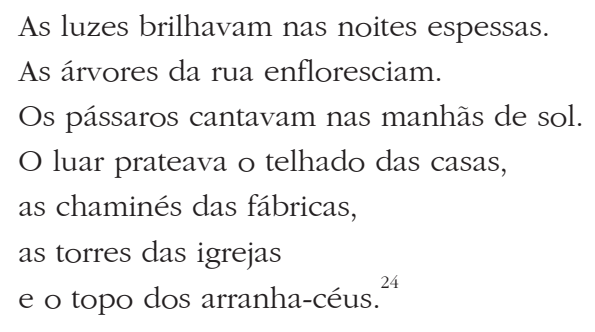

A arte de narrar do romancista guarda algumas surpresas para o leitor, como nesta passagem de grande densidade, em que o narrador se refere ao destino de seu primo Péricles, voluntarioso e autoritário quando criança (seu destino foi o oposto do destino do personagem narrador): "E o menino de vontade passou para o moço, do moço para o homem, do homem para o militar e do militar para o oficial, o comandante de soldados e batalhões" (p. 150).

Diante das poucas informações disponíveis sobre a vida do romancista, poder-se-ia tomar de empréstimo a esse romance um personagem nordestino, que veio parar em Belo Horizonte (não o narrador, que é natural do Serro). O romance dá as razões e narra sua vinda para essas paragens:

A ambição de correr o mundo: viajar. Sair de um estado pequeno e atrasado como era o seu e onde nunca seria nada. Vir para o Sul. Saltar um dia no Rio de Janeiro e ver a Guanabara, o Pão de Açúcar, o Corcovado. Visitar a Academia Brasileira de Letras e olhar para os seus quarenta imortais. Assenta praça no exército, no 29 B. C., com destino ao Rio. A vida da caserna. Os exercícios militares. Os dias de recruta na Vila Militar, donde é transferido para o 12 R. I. em Belo Horizonte. Revolução de 32 em São Paulo. Luta nas trincheiras. Irmãos contra irmãos. Completa o tempo de voluntariado e recebe baixa. ${ }^{25}$

24. Cf. GOMES. Obras reunidas: Romances, 1998, p. 123.

25. GOMES. Obras reunidas: Romances, 1998, p. 202. 
Teria o romancista José Bezerra Gomes vindo parar em Belo Horizonte por meios semelhantes? O livro recente de Joabel R. de Souza desfaz essa fantasia; segundo ele, o escritor veio estudar Direito em Belo Horizonte a convite de Osvaldo Bezerra de Araújo e Melo, veterinário, seu irmão mais velho, embora tenha prestado serviço militar pouco antes de sua vinda para o Sul. ${ }^{26}$

A história do personagem narrador, no plano romanesco, perdidas todas as oportunidades que se lhe apresentaram ao longo dos anos, termina assim:

Olho para a minha mesa cheia de garrafas secas e peço mais cerveja. Na rua, um retardatário passa cantarolando:

Saí de casa disposto a procurar

Aquela que há de ser a minha amada

Pois o meu coração é que me faz confessar

Que o homem sem mulher não vale nada...

Sinto, como uma punhalada, a letra do samba. Os bondes se recolheram e na rua só o bar onde bebo está aberto. O salão está vazio de um tudo e o garçom começa a cerrar as portas.

É noite alta e ainda bebo. ${ }^{27}$

O problema central da narrativa, colocado no título da obra - Por que não se casa, Doutor? -, reaparece no terceiro romance do autor, em que a ação se passa, de novo, no Rio Grande do Norte, na região algodoeira do Seridó: A porta e o vento, publicado em 1974, é o romance que quer ser poema - tal a sua densidade, tal a brevidade de seus capítulos e parágrafos. O romance tem 71 páginas na primeira edição e 57 nas Obras reunidas: Romances (1998) - dezessete capítulos ao todo. A narrativa se organiza em torno da casa grande, na fazenda, afastada da cidade, e "a casa da rua". Até o décimo segundo capítulo, as cenas se alternam: os capítulos ímpares na fazenda, os capítulos pares na cidade, onde residem Santos e sua prima Laura, cujos pais a enviaram para estudar no colégio. A partir do décimo terceiro capítulo, a ação continua na cidade, para onde trazem da casa grande o avô doente, no décimo sexto capítulo.

26. Cf. SouZA. Centenário de José Bezerra Gomes, p. 65 e p. 53-63.

27. GOMES. Obras reunidas: Romances, 1998, p.232. 
O personagem central dos capítulos pares, Santos, é um personagem meio aluado, semelhante ao Flávio de Por que não se casa, Doutor?, para quem tudo existe numa espécie de penumbra, tudo oscila entre sonho (acordado) e realidade. Nós, leitores, não conseguimos saber com certeza o que acontece a ele, tal o clima de sonolência e delírio que o cerca; os dados são por demais esgarçados. Sua prima Laura está ao seu lado, vivem na mesma casa, acompanhados apenas por uma serviçal; todos insinuam que eles devem se casar, ela própria o faz. Mas nada de casamento. Todos falam insistentemente de casamento a Santos ao longo do romance: "Precisa se casar, Santos. Moça é o que não falta no mundo..." (p. 240); "Já está bom de se casar, Santos?" (p. 256); "Já arranjou uma noiva, Santos?" (p. 265); "Só lhe falta uma noiva, Santos..." (p. 274); "Melhor, Santos? Quero vê-lo renovado... Pronto para pedir moça..." (p. 280).

O próprio escritor declarou certa vez a Franklin Jorge Roque que considerava $A$ porta e o vento um livro inacabado, e mais, que toda a sua obra, por causa da doença mental de que sofreu ao longo de quase toda a vida, ficara no meio do caminho. ${ }^{28}$

Para uma melhor compreensão da vocação poética do romance, sobre a qual o dado biográfico da doença lança uma luz de especial caráter humano, leia-se um poema do autor, algo equivalente a um dos capítulos do romance A porta e o vento (conforme se verá). Este foi um dos poemas escolhidos para figurar na antologia organizada pelas professoras Constância Lima Duarte e Diva Maria de Macedo:

\section{MEALHEIRO}

Meu avô

a camisa por cima da celoura

no mourão

da porteira do curral

de pau a pique

cheirando a estrume

Contando

os bezerros

novos

das vacas paridas

28. Cf. ROQue. In: SOUZA. Centenário de José Bezerra Gomes, p. 128. 
Minha avó

no santuário da capela

o rosário de contas

de capim santo

nas mãos devotas

Nos terços

nas novenas

de maio

o mês das flores

As espigas

de milho

verde

bonecando

nos roçados

Os algodoeiros

casulando

As ovelhas

malhando

na sombra

das quixabeiras

O rio

a cheia

A água

barrenta

da correnteza

transbordando

pelas vazantes do rio cheio

Os sapos

os cururus

cantando

dentro das noites

empoçadas 
As tanajuras
esvoaçando
na luz
das lamparinas

As flores

do mato crescendo

pelos caminhos orvalhados

rescendendo

Os meninos

gordos

de terra

sob a chuva

sob o inverno

se banhando

As veredas

trilhadas pelos preás

Os ninhos

dos concrizes

balançando

na copa das braúnas

As asas

dos urubus

pairando

paradas

no céu

encandeando

A barra das madrugadas

O aboio dos tangerinos
As alpregatas
de meu avô
arrastando
nas lajes do alpendre
do mundo
de minha infância. ${ }^{29}$

29. GOMES. Antologia poética, 1974, p. 17-20. 
Agora, leia-se um capítulo do romance $A$ porta e o vento - o primeiro capítulo, que com muito pouco esforço, à custa de uma poda, pôde ser reduzido à forma poemática (esse foi justamente o capítulo escolhido para figurar na antologia já mencionada):

\section{(Na Casa Grande)}

I.

Meu avô

camisa de algodão branco

por cima da calça de mescla

lenço de chita na mão trêmula

barba cobrindo o peito cabeludo

amanhecia gritando.

- Ainda estou vivo.

Quando eu morrer acabem o resto.

No banco de madeira do alpendre chamava pelos filhos.

- Terto! Ó Terto!

Meu avô assoava o catarro no lenço

sua voz percorria a casa toda.

A voz de meu avô

chegava aos ouvidos de minha avó.

- Fausta! Ó Fausta!

As alpargatas de meu avô

chiavam no corredor.

Os bilros da almofada de tia Ângela

estalavam no oitão.

Tropeiros passavam pela estrada grande

tangendo os comboios para a feira da rua. 
- Bom dia, major.

- Abanque-se, Pedro.

- A demora é pouca, major.

- Muito chovido no Brejo?

- Deixei debaixo de chuva, major.

- E como está a rapadura?

- Por um preção, major.

- Apanhou muito algodão, major?

- A safra é quase nenhuma.

Xico alugado banhava o cavalo do meu avô na praça da cacimba:

- Os espinhos do sertão

Trago todos na memória...

Mandacaru, xique-xique,

Macambira, palmatória...

II.

Do curral o mugido das vacas paridas

ovelhas pastavam no pátio

concrizes cantavam na copa dos pés de braúna da casa dos moradores a fumaça da maravalha.

No esteio do alpendre

o cavalo de tio Terto remoía o milho.

Preta

saía para o açude

com uma trouxa de roupa na cabeça.

Nos altos enjuremados

Crescia o capim panasco.

Nas fraldas dos cabeços

floravam os pés de umburana.

Bandos de marrecas

baixavam na represa do açude.

Moradores

passavam com as enxadas nos ombros. 
Vacas de leite chegavam para o curral

tio Terto apartava os bezerros novos.

Tia Ângela

aguava as plantas do jardim.

Cheiravam os cravos brancos estrumados.

Recendiam longe os pés de manjericões.

Nas noites de maio

a capela da casa grande

se enfeitava para as novenas. ${ }^{30}$

Não se pode saber se para o bem, se para o mal, se felizmente ou infelizmente, o poema narrativo no século XX continuou apegado aos mitos, como no Cobra Norato, de Raul Bopp, no Martim Cererê, de Cassiano Ricardo, no Iararana, de Sosígenes Costa. Dir-se-ia que o poema narrativo não se secularizou; não se modernizou (sob esse aspecto), não se tornou forma padrão, não se impôs aos escritores e ao público. Aliás, nem mesmo no século XIX isso aconteceu, a despeito de diversas tentativas (como as "ballatas" de Joaquim Norberto; como os contos em verso de Artur Azevedo e o conto em versos "Pálida Elvira", de Machado de Assis; como o romancete Voragem, de Joaquim Manuel de Macedo, etc.). É certo que podemos nos lembrar de "O padre e a moça", "A morte do leiteiro", "O caso do vestido", de "O marginal Clorindo Gato" e até mesmo do extraordinário "Desaparecimento de Luísa Porto", além de outros poemas de Carlos Drummond de Andrade. Mas em todos esses poemas, a carga de lirismo como que esmaga a narrativa. Talvez por isso, pelo fato de a forma laica da narrativa em versos não se haver fixado entre nós (na literatura erudita), o romance de José Bezerra Gomes, em particular A porta e o vento, quis continuar romance, não atendeu ao chamado da poesia, não assumiu a sua forma plena de poema.

30. Cf. GOMES. Obras reunidas: Romances, 1998, p. 235-237. 
José Bezerra Gomes: the novel wants to turn into a poem

\begin{abstract}
This article reviews José Bezerra Gomes' works, pointing to the poetic trend of the writer, who, yet in his novels, tended towards the compactness proper to poetic texts.
\end{abstract}

Keywords: 1930's Brazilian novel, Regionalistic fiction, José Bezerra Gomes.

$$
\text { Referências }
$$

AZEveDO, Arthur. Contos em verso. Rio de Janeiro: H. Garnier, 1910.

BUENO, Luís. Uma história do romance de 30. São Paulo: Edusp, 2006.

CIRNE, Moacy. Uma poesia desconhecida. Minas Gerais, Suplemento Literário, Belo Horizonte, v. 8, n. 349, p. 8-9, 5 maio 1973.

CIRNE, Moacy. José Bezerra Gomes e a vanguarda. Minas Gerais, Suplemento Literário, Belo Horizonte, v. 9, n. 393, p. 11, 9 mar. 1974.

CIRNE, Moacy. A poesia e o poema do Rio Grande do Norte. Natal: Fundação José Augusto, 1979.

COUTINHO, Afrânio. Dir. A literatura no Brasil. Rio de Janeiro: José Olympio, 1986. 6v.

DANTAS, Paulo. Romancista nordestino do ciclo do algodão. Minas Gerais, Suplemento Literário, Belo Horizonte, ano XV, n. 824, p. 8, 17 jul. 1982.

DUARTE, Constância Lima; MACEDO, Diva Maria Cunha Pereira de. Org. Literatura do Rio Grande do Norte: Antologia. Natal: Fundação José Augusto, 2001.

ENCICLOPÉDIA de literatura brasileira. Dir. Afrânio Coutinho e J. Galante de Sousa. Rio de Janeiro: Oficina Literária Afrânio Coutinho, 1990. 2 v.

GOMES, José Bezerra. Os brutos. Rio de Janeiro: Pongetti, 1938.

GOMES, José Bezerra. Retrato de Ferreira Itajubá (Ensaio de compreensão). Natal: Surto, 1944.

GOMES, José Bezerra. Antologia poética. Natal: Fundação José Augusto, 1974.

GOMES, José Bezerra. A porta e o vento. Natal: Fundação José Augusto, 1974.

GOMES, José Bezerra. Teatro de João Redondo. Natal: Fundação José Augusto, 1975.

GOMES, José Bezerra. Sinopse do município de Currais Novos (monografia ilustrada). Natal: Gráfica Manimbu, 1975.

GOMES, José Bezerra. Retrospecção da vida do presidente Tomás de Araújo Pereira. Natal: I. H. G. R. N., 1981. [Separata]

GOMES, José Bezerra. Obras reunidas: Romances. Natal: EDUFRN, 1998.

GOMES, José Bezerra. Obras reunidas: Ensaios. Natal: EDUFRN, 2004.

GOMES, José Bezerra. Os brutos. Natal: Sebo Vermelho, 2007. 
FUSCO, Rosário. Vida literária. São Paulo: Panorama, 1940.

LEITE, Otávio Dias. Poesia. Belo Horizonte: Imprensa Oficial do Estado de Minas Gerais, 1967.

LINHARES, Temístocles. História crítica do romance brasileiro. Belo Horizonte: Itatiaia, 1987. $3 \mathrm{v}$.

MARTINS, Wilson. História da inteligência brasileira. São Paulo: Cultrix, 1977-1979. 7 v.

MENESES, Raimundo de. Dicionário literário brasileiro. 2ed. Rio de Janeiro: Livros Técnicos e Científicos, 1978.

PAES, José Paulo; MOISÉS, Massaud. Org. Pequeno dicionário de literatura brasileira. São Paulo: Cultrix, 1967.

SOUZA, Joabel R. de. Centenário de José Bezerra Gomes. Currais Novos: Fundação Cultural "José Bezerra Gomes", 2011. 
